\title{
Periplasmic bacterial biomineralization of copper sulfide nanoparticles
}

\author{
Yeseul Park ${ }^{1}$, Zohar Eyal ${ }^{2}$, Péter Pekker ${ }^{3}$, Daniel M. Chevrier ${ }^{1}$, Christopher T. Lefèvre $^{1}$, Pascal \\ Arnoux $^{1}$, Jean Armengaud ${ }^{4}$, Caroline L. Monteil ${ }^{1}$, Assaf Gal $^{2}$, Mihály Pósfai ${ }^{3}$, Damien Faivre ${ }^{1}$ \\ ${ }^{1}$ Aix-Marseille Université, CEA, CNRS, BIAM, 13108 Saint Paul lez Durance, France \\ ${ }^{2}$ Department of Plant and Environmental Sciences, Weizmann Institute of Science, Rehovot, Israel \\ ${ }^{3}$ University of Pannonia, Research Institute of Biomolecular and Chemical Engineering, Nanolab, 8200 \\ Veszprém, Egyetem st. 10, Hungary \\ ${ }^{4}$ Université Paris-Saclay, CEA, INRAE, Département Médicaments et Technologies pour la Santé (DMTS), SPI, \\ F-30200, Bagnols-sur-Cèze, France \\ * Correspondence : damien.faivre@cea.fr
}

\begin{abstract}
Metal sulfides are a common group of extracellular bacterial biominerals. Only few cases of intracellular biomineralization have been reported in this group, mostly limited to greigite $\left(\mathrm{Fe}_{3} \mathrm{~S}_{4}\right)$ in magnetotactic bacteria. Here, we report the intracellular but periplasmic biomineralization of copper sulfide by the magnetotactic bacterium Desulfamplus magnetovallimortis (strain BW-1) that is known to mineralize greigite and magnetite $\left(\mathrm{Fe}_{3} \mathrm{O}_{4}\right)$ in the cytoplasm. BW-1 produces hundreds of spherical nanoparticles, composed of 1-2 nm substructures of a poorly crystalline hexagonal copper sulfide that remains in a thermodynamically unstable state. Differential proteomics suggests that periplasmic proteins, such as a DegP-like protein and a heavy metal-binding protein, could be involved in this process. The unexpected periplasmic formation of copper sulfide nanoparticles in BW-1 reveals previously unknown possibilities for intracellular biomineralization.
\end{abstract}

\section{Main Text}

Various organisms produce inorganic minerals through a process called biomineralization (1). According to the original Lowenstam's definition, biomineralization can be classified into biologically-induced and biologically-controlled processes The first case mainly attributes to interactions between metabolic byproducts and environments and leads to particles with heterogeneous properties (2). The latter occurs under strict cellular control (3). Such biomineralization processes often lead to materials with highly controlled particle dimension and organization, defined location of nucleation, and compartmentalization, thus yielding uniform nano- and microstructured materials with potential for numerous applications (4).

Microbial biomineralization contributes to the formation of both extracellular and intracellular biominerals (5). In particular, sulfate-reducing bacteria (SRB) play an important role in the environment, by producing diverse extracellular biominerals, especially metal sulfides (6). In contrast, only a few cases of intracellular metal sulfide biomineralization have been identified in microorganisms, representatively $\mathrm{CdS}(7)$ and $\mathrm{Fe}_{3} \mathrm{~S}_{4}(8-10)$. Microorganisms with the strictest control over biomineral structures are known to be magnetotactic bacteria, 
which form magnetosomes, organelles consisting of either greigite $\left(\mathrm{Fe}_{3} \mathrm{~S}_{4}\right)$ or magnetite $\left(\mathrm{Fe}_{3} \mathrm{O}_{4}\right)$ crystals in lipidic vesicles localized within the cytoplasm (11).

Here, we report the intracellular biomineralization of copper sulfide in the magnetotactic bacterium Desulfamplus Magnetovallimortis strain BW-1 (12). This bacterium produces hundreds of spherical nanoparticles of about $70 \mathrm{~nm}$ within the periplasmic space. Each particle is composed of nano-sized building blocks with crystallographic domains reminiscent of hexagonal CuS phases that are thermodynamically not stable. Differential proteomic analysis points towards putative periplasmic proteins that could be responsible for the biomineralizing process.

The bacterial strain we used is a sulfate-reducer and the only isolated case among greigite-producing magnetotactic bacteria. This bacterium is capable of biomineralizing both magnetite and greigite (12-13). As environmental greigite producers commonly contain significant amount of copper in their biomineral (14), we hypothesized that greigite biomineralization by BW-1 could be influenced by copper. We thus increased copper concentration in the medium up to $13.9 \mu \mathrm{M}$. Instead of any impact on greigite biomineralization, we discovered that BW-1 produces hundreds of nanoparticles inside the cell body. The particles show different morphological features than magnetosome particles or extracellular precipitates (Fig. 1A, Fig. S1). The nanoparticles appear spherical and separated from each other, with a narrow size distribution $(69 \pm 15 \mathrm{~nm})$. The number of particles per cell is $344 \pm 76$ (10 cells analyzed) (Fig. 1C). These particles are absent in the $\mathrm{Cu}$ concentration used in the culture medium used for greigite biomineralization $(0.73 \mu \mathrm{M})$.

As demonstrated in Fig. 1B, the nanoparticles are mainly composed of copper and sulfur. The distribution of both elements is similar in each particle and there is no noticeable accumulation of these elements apart from the particles (Fig. S2B, Fig. S3D). Iron phosphorusrich granules frequently observed in anaerobic bacteria, such as ferrosomes that have similar morphological features as these particles (15), were not observed. Quantitative EDXS analysis revealed an averaged elemental ratio of $\mathrm{Cu} / \mathrm{S}$ of $1.39 \pm 0.15$ (Fig. S2C). The copper sulfide crystal phase with the closest $\mathrm{Cu} / \mathrm{S}$ ratio is hexagonal copper sulfide spionkopite $\left(\mathrm{Cu}_{39} \mathrm{~S}_{28}, \mathrm{Cu} / \mathrm{S}\right.$ ratio 1.39).

Looking in more details with high-resolution TEM (HRTEM), the particles remarkably consist of 1 to $2 \mathrm{~nm}$-sized substructures, which are in the similar size range as CdS-capping agent complexes reported in yeasts (16) (Fig. 1D). Fast Fourier Transforms (FFTs) of HRTEM images of single particles show two faint rings with several diffuse reflections within the rings (Fig. 1E). This indicates that the individual crystallites are not coaligned, and nm-sized. The two d-spacing values, obtained from the FFT, range between 3.04 and $3.08 \AA$ (the inner ring) and between 1.86 and $1.90 \AA$ (the outer ring). These values match those of the two most intense reflections of hexagonal copper sulfides, including covellite, spionkopite and yarrowite (in covellite $1.897 \AA$ corresponds to $\mathrm{d}(110)$ and $3.048 \AA$ to $\mathrm{d}(102)$ ) (17-18). One of the strongest reflections of covellite at $2.7 \AA$ (006) did not appear (19). Similar values also exist in chalcocite, despite the slightly larger spacings (1.980 and $3.06 \AA$ for $\mathrm{d}(110)$ and $\mathrm{d}(101)$, respectively). On the other hand, the diffraction data do not match spacings in other common copper sulfide minerals that have cubic close-packing of sulfur (digenite, geerite, anilite). Accordingly, both 
1 elemental composition and structural data suggest that their constituent crystallites have 2 hexagonal packing of sulfur layers on the short range.

3 We collected $\mathrm{Cu}$ K-edge X-ray absorption spectroscopy (XAS) data on individual BW41 cells to examine them from the local structural perspective. Based on the pre-edge $(1 \mathrm{~s} \rightarrow 3 \mathrm{~d})$ 5 and rising edge $(1 \mathrm{~s} \rightarrow 4 \mathrm{p})$ near-edge features, the XAS spectrum of a BW-1 cell (Fig. 1F, Fig. 6 S3) shows more similar features to $\mathrm{Cu}_{2} \mathrm{~S}$ than $\mathrm{CuS}$, which also indicates less $\mathrm{Cu}^{2+}$ in the 7 biomineral composition. Specifically, the characteristic rising edge feature from $\mathrm{CuS}(\sim 8986$ $8 \mathrm{eV}$ ) and more prominent pre-edge feature (spin-forbidden $1 \mathrm{~s} \rightarrow 3 \mathrm{~d}^{9}$ transition for $\mathrm{Cu}^{2+}$ centers) 9 are absent in the BW-1 sample (20). Moreover, $\mathrm{Cu}_{2} \mathrm{~S}$ and the cell sample have similar 10 absorption edge positions and relatively weak near-edge features. Combining TEM and XAS data, the observed features of the copper sulfide particles are consistent with the properties of a "primitive copper sulfide precipitate" described by Pattrick et al. (21): the material has a covellite-type short-range order, and contains $\mathrm{Cu}(\mathrm{I})$, mostly in trigonal coordination. 
A

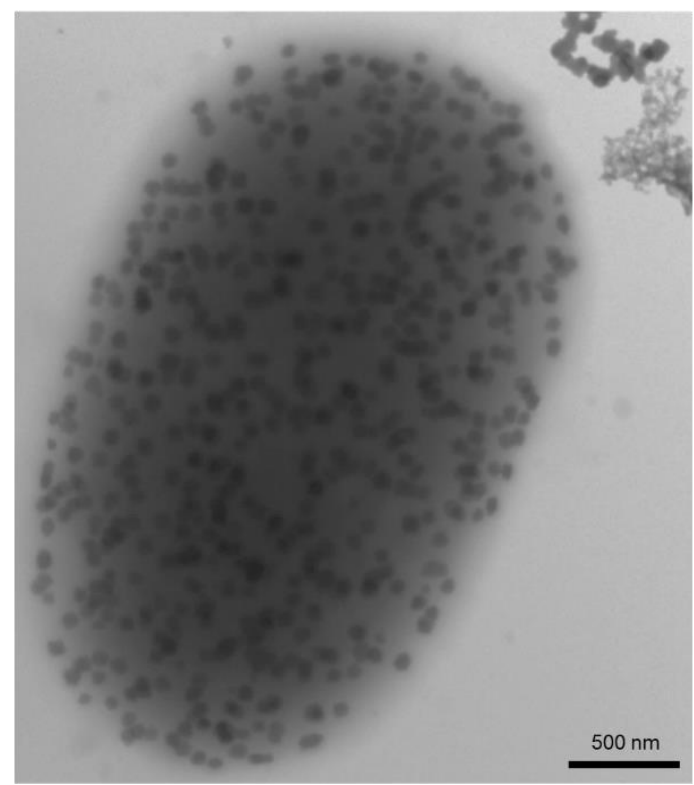

C

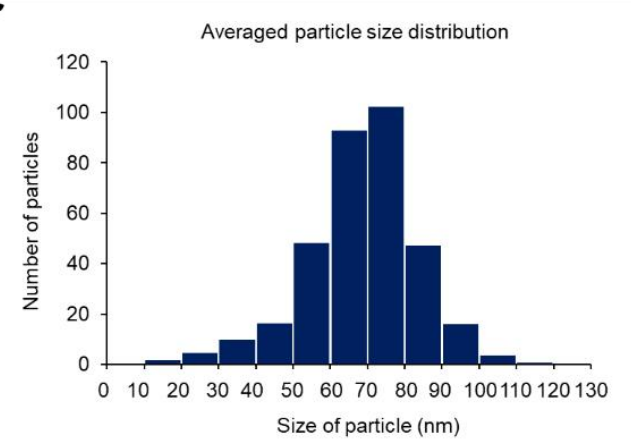

B
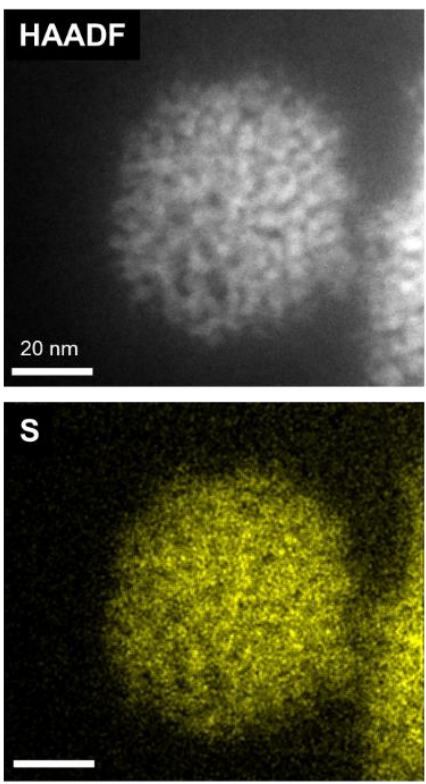

D

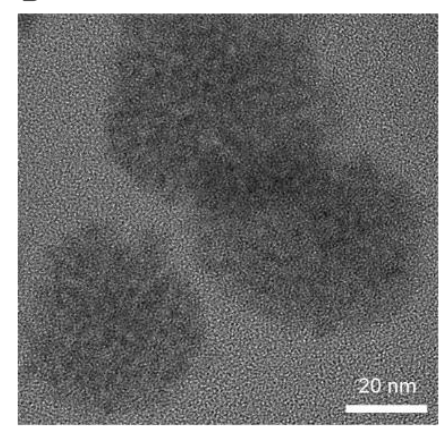

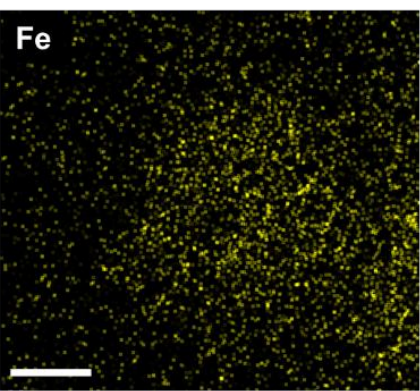

Cu

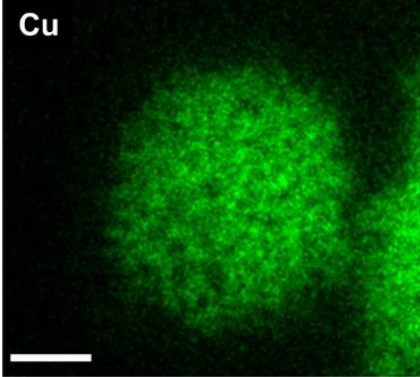

E

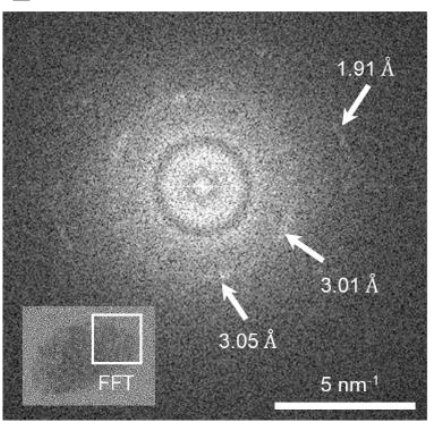

$\mathbf{F}$
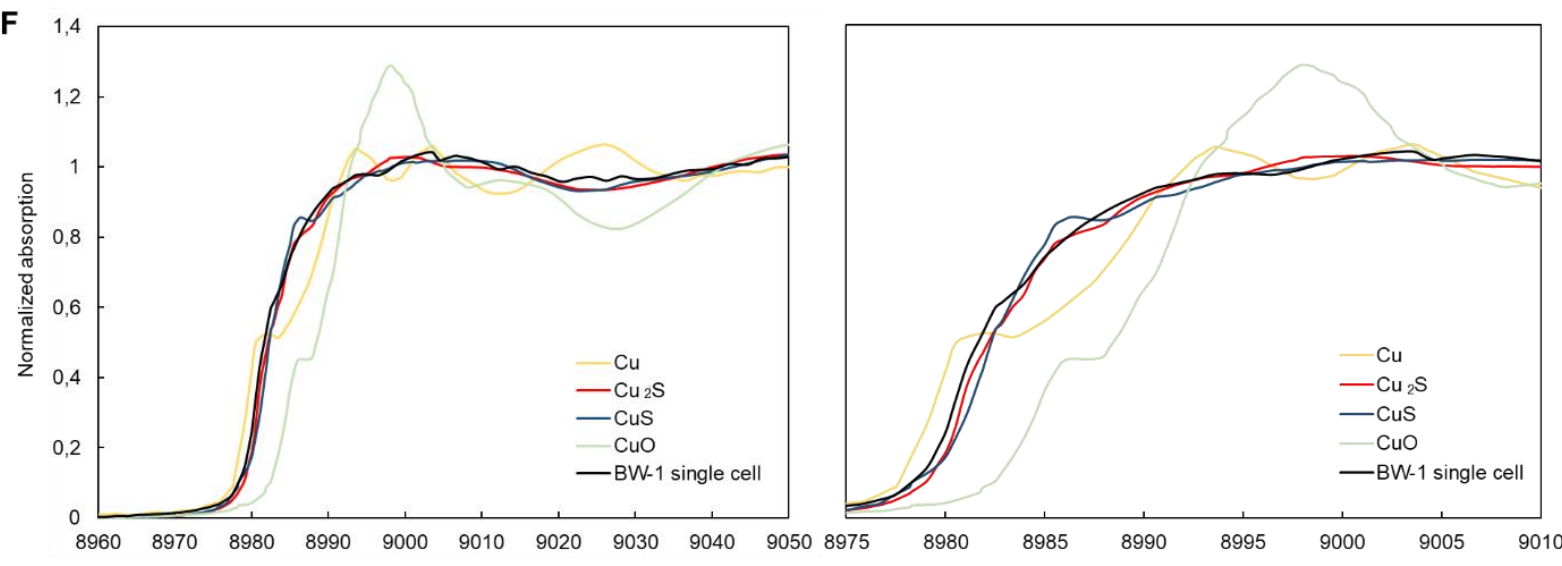

Energy $(\mathrm{eV})$

Fig. 1. Morphological and chemical analysis of copper sulfide nanoparticles produced by BW-1. (A) A BW-1 cell filled with intracellular nanoparticles, showing distinct featured from extracellular precipitates imaged by TEM. (B) HAADF STEM image showing a single copper sulfide nanoparticle in a BW-1 cell and STEM EDS element maps of Fe, $\mathrm{S}$, and Cu, respectively. (C) Size distribution of particles (10 bacteria). (D) HRTEM image of copper sulfide particles, composed of 1-2 nm-sized substructures. (E) Fourier transform of the boxed area in the inset, showing two faint rings and some diffuse spots. (F) Normalized Cu K-edge XAS spectra from an entire single cell presented in Fig. S3 together with reference materials. 
In order to elucidate the cellular localization of the mineral particles, we performed cryoelectron tomography (cryo-ET) of hydrated cells to investigate the native-state organization of the bacteria. A slice in the tomogram reconstruction in Fig. $2 \mathrm{~A}$ and the $3 \mathrm{D}$ volume rendering in Fig. 2B clearly indicate that the nanoparticles are localized inside the periplasmic space. Some particles locally distort the inner membrane and extend the surrounding periplasmic area (Fig. 2C, Fig. S4).

A

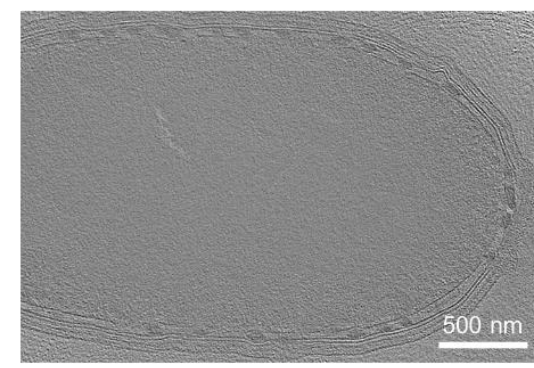

B

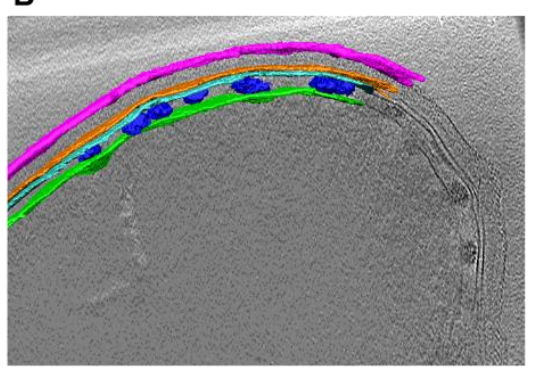

c

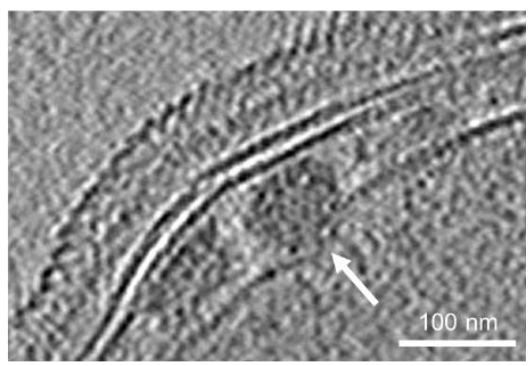

Fig. 1. Location of intracellular copper sulfide nanoparticles in BW-1 and particle observation. (A) Cryogenic electron microscopy (cryo-EM) tomographic slice of a BW-1 cell. (B) Volume rendering of the intracellular particles and four cell membranes (magenta: S-layer, orange: outer membrane, cyan: peptidoglycan layer and green: plasma membrane) overlapped on a cryo-EM tomographic slice. (C) Cryo-EM tomographic slice focused on copper sulfide nanoparticles. A white arrow indicates an expanded part of the periplasmic space due to the presence of a copper sulfide particle.

As biologically-controlled biomineralization typically occurs within an organic matrix (1), we searched for such configuration. After rupturing the BW-1 cells, we deposited the particles onto a TEM grid. Comparing particles that were not stained (Fig. 3A, Fig. S5A), a pattern of an encompassing substance was observed on every particle (Fig. 3B, Fig. S5B). Given the absence of distinct phosphorus signal around the particle (Fig. S2B), it may not be a typical lipidic membrane but a different type of organic matrix composed of a macromolecular complex.

A

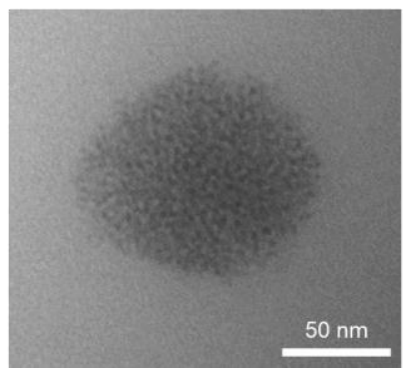

B

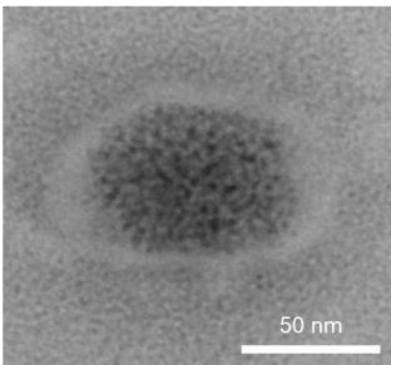

Fig. 3. Particles extracted from cells using a cell disruptor and deposited onto EM grids. (A) Particle before staining. (B) Particle showing a potential macromolecular complex after a staining with sodium tungstate $2 \%(\mathrm{w} / \mathrm{v})$. 
We next conducted a differential label-free shotgun proteomics comparison using nanoLC-tandem MS (22) based on the BW-1 annotated genome (23) to identify candidate proteins associated with this biomineralization process. We compared the abundance of proteins present in the total cell fraction of strain BW-1 that was cultured in a copper-rich condition $(13.9 \mu \mathrm{M})$ and in a copper-poor condition $(0.73 \mu \mathrm{M})$, in which cells respectively form and do not form copper sulfide nanoparticles. Hypothesizing that biomineralizing proteins are more abundant in cell extracts of the copper-rich condition, we listed significantly up-detected proteins in cells in these conditions (Table S1).

Significant fold change was observed for two periplasmic proteins localized on different scaffolds of the genome. The one with the highest fold change (x2.2), whose sequence is found in MicroScope database under the accession number MTBBW1_v2_2110004, is homologous to the periplasmic serine endoprotease DegP and represents up to $0.19 \%$ of the total detected proteome. In the BW-1 genome, this gene is adjacent to a classical membrane-bound histidine kinase and a cytoplasmic response-regulator. This organization is highly similar to the twocomponent (TC) CusS/CusR regulatory system involved in copper homeostasis (24) (Fig. 4A). In addition, this region is flanked downstream by an inner membrane metabolite transporter, a NAD-dependent epimerase/dehydratase, a NAD(P)/FAD-dependent oxidoreductase and a malEGK operon involved in maltose uptake, while a full rnfABCDGEH operon is located upstream. Some of these genes have iron-sulfur centers that can participate in oxido-reduction processes, whose role in periplasmic biomineralization should be investigated.

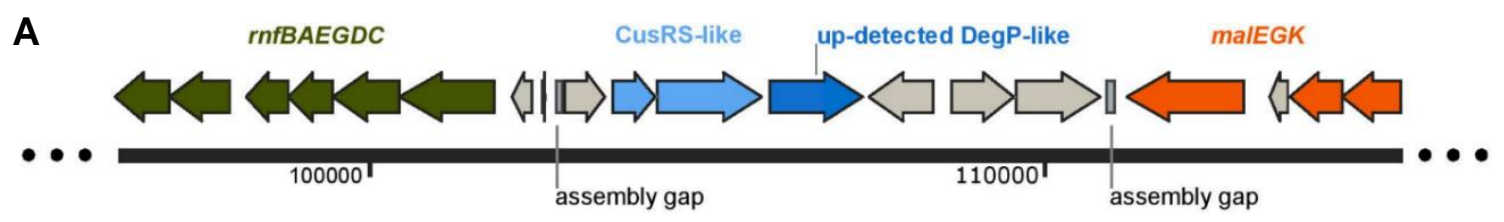

B

MTBBW1_V2_2110004, DegP-like periplasmic serine endoprotease

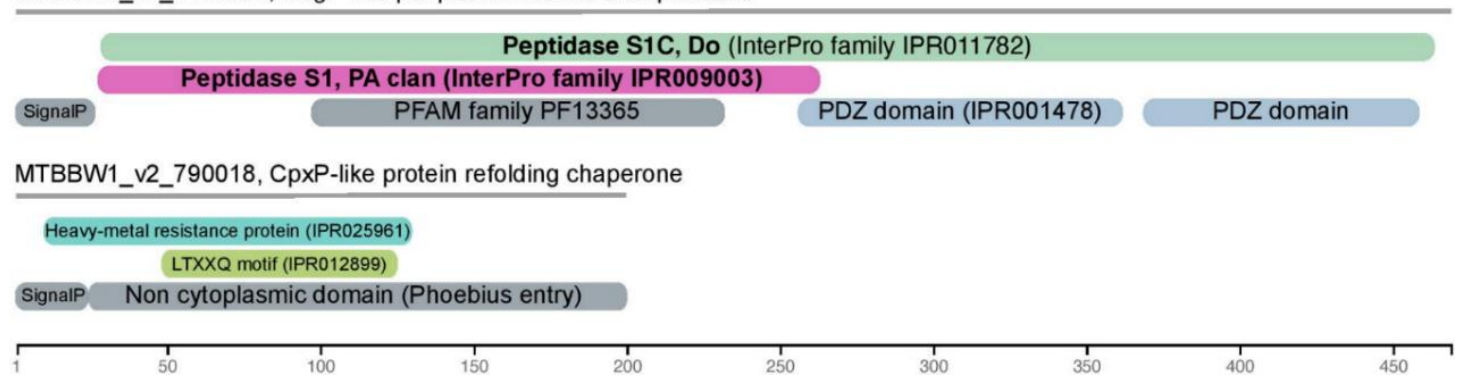

Fig. 4. Genomic and proteomic information associated to selected up-detected periplasmic proteins in cells producing copper sulfide particles. (A) Genomic region of the up-detected DegP-like protein MTBBW1_v2_2110004. (B) Domain architecture of two up-detected putative periplasmic proteins involved in copper sulfide biomineralization.

The DegP-like protein consists of a N-terminal protease domain coupled to two PDZ domains (Fig. 4B). The protease domain shares a high degree of sequence identity (48\% on average) with the N-terminal region of MamE paralogs detected in BW-1 and Magnetospirillum 
magneticum AMB-1 genomes. MamE belongs to the HtrA/DegP family and is required for continued growth of magnetite crystals in the magnetotactic Magnetospirillum magneticum AMB-1 (25). However, MTBBW1_v2_2110004 does not have CXXCH heme-binding motifs required for magnetite biomineralization. If it is involved in the formation of copper-sulfide particles, its activity in crystal nucleation or growth could be indirect. DegP proteases are known to act like chaperones and activate pathways by proteolysis of other periplasmic proteins. In Escherichia coli, the periplasmic endoprotease DegP is known to be involved in the Cpx envelope stress response to cope with stressful conditions (26). In this process, DegP-dependent proteolysis of the CpxP protein lifts the inhibition of the Cpx pathway, inducing the expression of other envelope protein folding and degrading factors. Interestingly, another up-detected, putatively periplasmic protein (MTBBW1_v2_790018, representing $0.34 \%$ of the total proteome) is composed of a CpxP-like motif LXXTQ (Fig. 4B), suggesting that it could have similar interactions with DegP homologs, like as the protein MTBBW1_v2_2110004. Moreover, the latter protein belongs to a metal-binding protein family, whose members were shown to bind zinc or copper (27).

Altogether, our proteomics data support the scenario: sulfide ion generated by sulfate reduction and copper ion accumulated into the periplasmic space form particles by activating a specific regulatory pathway, an endoprotease and heavy metal-binding proteins whose interactions could lead to the particle formation. The surprising biomineralization in the periplasm could consist in a strategy to detoxify the cell, raising questions about the fate of the particles once biomineralized. Future experiments, including spectroscopic, comparative genomics, transcriptomics and directed genetic approaches will allow to test these hypotheses and explain how a simple microorganism is capable of controlling three types of biomineral formation in two types of locallizations while also stabilizing an unstable mineral phases. 


\section{References and Notes}

1. H. A. Lowenstam, Minerals formed by organisms. Science 211, 1126-1131 (1981).

2. S. Douglas, T. J. Beveridge, Mineral formation by bacteria in natural microbial communities. FEMS Microbiol. Ecol. 26, 79-88 (1998).

3. D. Bazylinski, R. B. Frankel, Biologically Controlled Mineralization in Prokaryotes. Rev. Mineral. Geochem. 54, 217-247 (2003).

4. A. Veis, "Crystals and Life: An Introduction" in Biomineralization. From Nature to Application (Wiley, ed. 4, 2008), pp. 1-35.

5. W. Qin, C. Wang, Y, Ma, M. Shen, J. Li, K. Jiao, F. R. Tay, L. Niu, Microbe-Mediated Extracellular and Intracellular Mineralization: Environmental, Industrial, and Biotechnological Applications. Adv. Mater. 32, 1907833 (2020).

6. G. Muyzer, A. J. M. Stams, The ecology and biotechnology of sulphate-reducing bacteria. Nat. Rev. Microbiol. 6, 441-454 (2008).

7. C. T. Dameron, R. N. Reese, R. K. Mehra, A. R. Kortan, P. J. Carroll, M. L. Steigerwald, L. E. Brus, D. R. Winge, Nature 338, 596-597 (1989).

8. S. Mann, et al. Biomineralization of ferrimagnetic greigite (Fe3S4) and iron pyrite (FeS2) in a magnetotactic bacterium. Nature 343, 258-261 (1990).

9. M. Farina, D. M. S. Esquivel, H. G. P. Lins de Barros, Magnetic iron-sulphur crystals from a magnetotactic microorganism. Nature 343, 256-258 (1990).

10. M. Pósfai, P. R. Buseck, D. A. Bazylinski, R. B. Frankel. Reaction Sequence of Iron Sulfide Minerals in Bacteria and Their Use as Biomarkers. Science 280, 880-883 (1998).

11. F. Abreu, K. T. Silva, M. Farina, C. N. Keim, U. Lins. Greigite magnetosome membrane ultrastructure in 'Candidatus Magnetoglobus multicellularis'. Int. Microbiol. 11, 75-80 (2008).

12. C. T. Lefèvre, N. Menguy, F. Abreu, U. Lins, C. T. M. Pósfai, T. Prozorov, D. Pignol, R. B. Frankel, D. A. Bazylinski. A Cultured Greigite-Producing Magnetotactic Bacterium in a Novel Group of Sulfate-Reducing Bacteria. Science 334, 1720-1723 (2011).

13. E. C. T. Descamps, C. L. Monteil, N. Menguy, N. Ginet, D. Pignol, D. A. Bazylinski, C. T. Lefèvre. Desulfamplus magnetovallimortis gen. nov., sp. nov., a magnetotactic bacterium from a brackish desert spring able to biomineralize greigite and magnetite, that represents a novel lineage in the Desulfobacteraceae. Syst. Appl. Microbiol. 40, 280-289 (2017).

14. M. Posfai, M., et al. Iron sulfides from magnetotactic bacteria; structure, composition, and phase transitions. Am. Mineral. 83, 1469-1481 (1998).

15. C. R. Grant, A. Komeili, https://biorxiv.org/content/10.1101/2020.01.10.902569v1 (2020). 
16. W. Bae, W, R. K. Mehra, Properties of glutathione- and phytochelatin-capped CdS bionanocrystallites. J. Inorg. Biochem. 69, 33-43 (1998).

17. D. T. Rickard, Covellite formation in low temperature aqueous solutions. Mineralium Deposita 7, 180-188 (1972).

18. R. J. Goble, COPPER SULFIDES FROM ALBERTA: YARROWITE $\mathrm{CU}_{9} \mathrm{~S}_{8}$ AND SPIONKOPITE $\mathrm{CU}_{39} \mathrm{~S}_{28}$. Canad. Mineral. 18, 511-518 (1980).

19. D. A. Islam, A. Chakraborty, B. Bhattacharya, U. Sarkar, H. Acharya, Tailored synthesis of $\mathrm{CuS}$ nanodisks from a new macrocyclic precursor and their efficient catalytic properties on methylene blue dye degradation. J. Nanopart. Res. 18, 114 (2016).

20. P. Kumar, R. Nagarajan, R. Sarangi, Quantitative X-ray absorption and emission spectroscopies: electronic structure elucidation of $\mathrm{Cu}_{2} \mathrm{~S}$ and $\mathrm{CuS}$. J. Mater. Chem. C 1, 24482454 (2013).

21. R. A. D. Pattrick, J. F. W. Mosselmans, J. M. Charnock, K. E. R. England, G. R. Helz, C. D. Garner, D. J. Vaughan, The structure of amorphous copper sulfide precipitates: An X-ray absorption study. Geochim. Cosmochim. Acta. 61, 2023-2036 (1997).

22. D. Gouveia, L. Grenga, O. Pible, J. Armengaud, Quick microbial molecular phenotyping by differential shotgun proteomics. Environ. Microbiol. 22, 2996-3004 (2020).

23. C. T. Lefèvre, D. Trubitsyn, F. Abreu, S. Kolinko, C. Jogler, L. G. P. de Almeida, A. T. R. de Vasconcelos, R. Reinhardt, U. Lins, D. Pignol, D. Schüler, D. A. Bazylinski, N. Ginet, Comparative genomic analysis of magnetotactic bacteria from the Deltaproteobacteria provides new insights into magnetite and greigite magnetosome genes required for magnetotaxis. Environ. Microbiol. 15, 2712-2735 (2013).

24. D. K. C. Fung, Y. Ma, T. Xia, J. C. H. Luk, A. Yan, Signaling by the heavy-metal sensor CusS involves rearranged helical interactions in specific transmembrane regions. Mol. Microbiol. 100, 774-787 (2016).

25. A. Quinlan, D. Murat, H. Vali, A. Komeili, The HtrA/DegP family protease MamE is a bifunctional protein with roles in magnetosome protein localization and magnetite biomineralization. Mol. Microbiol. 80, 1075-1087 (2011).

26. D. R. Buelow, T. L. Raivio, Cpx Signal Transduction Is Influenced by a Conserved NTerminal Domain in the Novel Inhibitor CpxP and the Periplasmic Protease DegP. J. Bacteriol. 187, 6622-6630 (2005).

27. G. Pompidor, A. P. Maillard, E. Girard, S. Gambarelli, R. Kahn, J. Covès, X-ray structure of the metal-sensor CnrX in both the apo- and copper-bound forms. FEBS Lett. 582, 39543958 (2008).

28. E. M. Hartmann, F. Allain, J. Gaillard, O. Pible, J. Armengaud, Taking the Shortcut for High-Throughput Shotgun Proteomic Analysis of Bacteria. in Host-Bacteria Interactions: Methods and Protocols (Springer, New York, 2014), pp. 275-285. 
29. G. Klein, C. Mathé, M. Biola-Clier, S. Devineau, E. Drouineau, E. Hatem, L. Marichal, B. Alonso, J. Gaillard, G. Lagniel, J. Armengaud, M. Carrière, S. Chèdin, Y. Boulard, S. Pin, J. Renault, J. Aude, J. Labarre, RNA-binding proteins are a major target of silica nanoparticles in cell extracts. Nanotoxicology 10, 1555-1564 (2016).

30. D. Vallenet, A. Calteau, M. Duboi, P. Amours, A. Bazin, M. Beuvin, L. Burlot, X. Bussell, S. Fouteau, G. Gautreau, A. Lajus, J. Langlois, R. Planel, D. Roche, J. Rollin, Z. Rouy, V. Sabatet, C. Médigue. MicroScope: an integrated platform for the annotation and exploration of microbial gene functions through genomic, pangenomic and metabolic comparative analysis. Nucleic Acids Res. 48, D579-D589 (2020).

\section{Acknowledgements}

We thank all members of the MEM team and Magali Floriani from IRSN for their assistance with the work. We would like to acknowledge Diamond Light Source for beamtime on Beamline I-14 under proposals MG23693-1 (preliminary data) and MG23602-1 (presented data). We thank Dr. Fernando Cacho-Nerin and the staff at I14 for their support during beamtime. We also give thanks to Dr. Eva Pereiro of beamline MISTRAL at ALBA Synchrotron for technical support during our preliminary measurements. We thank Alain Manceau of ISTerre Grenoble for providing reference data for single cell XANES analysis. Financial support was provided by the CEA via a CFR doctoral fellowship to YP. DMC. acknowledges research funding through a European Union Marie-Skłodowska Curie Action International Fellowship (MSCA-IF Project 797431: BioNanoMagnets).

\section{Competing interests}

Authors declare that they have no competing interests.

\section{Data and materials availability}

Mass spectrometry proteomics data were submitted to the ProteomeXchange Consortium via the PRIDE partner repository under dataset identifiers PXD021XYZ and 10.6019/PXD021XYZ [The reviewers may access this private dataset using reviewer_pxd021XYZ@ebi.ac.uk as Username and ZWXCVGZW as Password]. The functional annotation used in this study is publically available on the Microscope platform (https://mage.genoscope.cns.fr/). 


\section{Material and Methods}

\section{Cell culture}

Pre-culture preparation: BW-1 cells were first cultured at $28{ }^{\circ} \mathrm{C}$ in a culture medium of $\mathrm{Cu}$ (II) $0.73 \mu \mathrm{M}$ and $\mathrm{Fe}$ (II) $1 \mu \mathrm{M}$. In this culture condition, the bacteria rarely produce copper-based or iron-based intracellular biominerals.

Cell culture preparation to produce particles: Once the pre-culture was enriched with motile cells (cell concentration $>2 \cdot 10^{7}$ cells $/ \mathrm{ml}$ ), cells were centrifuged down and inoculated to a new culture medium containing enhanced concentration of $\mathrm{Cu}$ (II) $13.9 \mu \mathrm{M}$ and $\mathrm{Fe}$ (II) $20 \mu \mathrm{M}$. The initial cell density was controlled below $10^{6}$ cells $/ \mathrm{ml}$ to maintain the amount of extracellular precipitates produced by cellular metabolites and metal ion concentration in the medium. The cell culture was kept in the dark at the temperature $28{ }^{\circ} \mathrm{C}$ for 20 hours to make cells produce copper sulfide particles.

The culture medium used for BW-1 culture contains (per liter): $20 \mathrm{~g} \mathrm{NaCl}, 3 \mathrm{~g} \mathrm{MgCl}_{2} \cdot 6 \mathrm{H}_{2} \mathrm{O}, 3$ g Na $2 \mathrm{SO}_{4}, 0.2 \mathrm{~g} \mathrm{CaCl}_{2} \cdot 2 \mathrm{H}_{2} \mathrm{O}$ and $0.5 \mathrm{~g} \mathrm{KCl}, 5 \mathrm{ml}$ modified Wolfe's mineral elixir (20), $0.3 \mathrm{~g}$ $\mathrm{NH}_{4} \mathrm{Cl}, 4.8 \mathrm{~g}$ HEPES and $2 \mathrm{~g}$ fumaric acid. After the $\mathrm{pH}$ value was adjusted to 7.2 with $5 \mathrm{M}$ $\mathrm{NaOH}$, the medium was autoclaved. Once the medium was cooled down to room temperature, $0.5 \mathrm{~mL}$ of an anaerobic stock solution of vitamins (20), $1.8 \mathrm{~mL}$ of $0.5 \mathrm{M} \mathrm{KHPO}_{4}$ buffer $(\mathrm{pH}$ 7.0), $0.4 \mathrm{~g}$ of sterilized cysteine were added. $\mathrm{Cu}(\mathrm{II})$ and $\mathrm{Fe}(\mathrm{II})$ concentrations were adjusted by adding $\mathrm{FeSO}_{4} \cdot 7 \mathrm{H}_{2} \mathrm{O}$ solution and $\mathrm{CuSO}_{4} \cdot 5 \mathrm{H}_{2} \mathrm{O}$ solution according to the need for each experiment. After all additives were added, the culture bottles were closed with septum caps and purged with $\mathrm{N}_{2}$ for $30 \mathrm{~min}$.

\section{$T E M$}

Cell and particle images were recorded on Ni grids coated with carbon film with a Tecnai G2 BioTWIN transmission electron microscope (FEI Company) at $100 \mathrm{kV}$ acceleration voltage. The number of particles on TEM images were manually counted using ImageJ software. Isolated particles were prepared in three steps: (1) filtration of cells with filter papers having 8 $\mu \mathrm{m}$ pore size; (2) ultracentrifugation with sucrose gradients of $50,60,70 \%(\mathrm{w} / \mathrm{w})$ to remove precipitates found under sucrose gradient of $70 \%(\mathrm{w} / \mathrm{w})$ and collect cells under sucrose gradient of 50\% (w/w) and 60\% (w/w); (3) cell disruption was carried out using a disruptor at 2,000 bar. After cell disruption, particles were dyed either with $2 \%(\mathrm{w} / \mathrm{v})$ sodium tungstate solution for 5 minutes or with $0.5 \%(\mathrm{w} / \mathrm{v})$ uranyl acetate for 2 minutes.

For ultra-thin sectons, BW-1 cells were fixed in a buffer prepared in the artificial seawater of the BW-1 medium containing $2.5 \%(\mathrm{w} / \mathrm{v})$ glutaraldehyde and $0.1 \mathrm{M}$ sodium cacodylate, $\mathrm{pH} 7$. Cells were kept at $4{ }^{\circ} \mathrm{C}$ for at least $24 \mathrm{~h}$. Cells were then postfixed for $1 \mathrm{~h}$ with $1 \%(\mathrm{w} / \mathrm{v})$ of osmium tetroxide. Cells were then dehydrated with successive ethanol baths with increasing concentrations and finally embedded in the resin (Epon 812). Sections (nominal thickness $\sim 50$ 
$\mathrm{nm}$ ) were made with the ultramicrotome UC7 (Leica Microsystems GmbH), deposited onto TEM copper grids coated with carbon film and stained with Uranyless ${ }^{\circledR}$ and lead citrate.

\section{HRTEM, STEM-HAADF and STEM-EDS}

In order to understand chemical compositions and structures of the particles, we used a ThermoFisher Talos F200X G2 scanning transmission electron microscope at $200 \mathrm{kV}$ accelerating voltage. Bright-field and HRTEM images and selected-area electron diffraction (SAED) patterns were obtained in TEM mode and recorded on a $4 \mathrm{k}$ x $4 \mathrm{k}$ Ceta camera. In STEM mode high-angle annular dark-field (HAADF) images were collected with $10.5 \mathrm{mrad}$ beam convergence angle. EDS mapping in STEM mode was performed with $10 \mu \mathrm{s}$ dwell time. Electron tomography was performed in STEM mode, with HAADF images acquired at $2^{\circ}$ specimen tilt intervals within a range of $\pm 70^{\circ}$.

\section{Scanning X-ray fluorescence microscopy (SXFM) and Cu K-edge X-ray absorption spectroscopy $(X A S)$}

TEM grids of BW-1 cells were mounted for measurement at the I-14 hard X-ray nanoprobe beamline (Diamond Light Source Ltd., Didcot, UK) using custom holders designed and supplied by the beamline. SXFM measurements were conducted under ambient conditions using an incident photon energy of $9 \mathrm{keV}$ for X-ray fluorescence (XRF) mapping. The focused $\mathrm{X}$-ray beam was measured to be $\sim 50-60 \mathrm{~nm}$ in size during the beamtime. X-ray fluorescence from the sample was collected in front of the sample using a four-element silicon drift detector (RaySpec, UK). A raster scanning step size of $50 \mathrm{~nm}$ was used for high resolution maps with a dwell time of $20 \mathrm{~ms}$. To collect $\mathrm{Cu}$ K-edge XAS on a single cell of BW-1, maps of $\mathrm{Cu} \mathrm{K} \alpha \mathrm{XRF}$ were collected from 8.8-9.2 $\mathrm{keV}$ and post-aligned using the $\mathrm{Ca} \mathrm{K} \alpha$ signal of a background feature. Dawn software was used to interpret collected XRF maps and extract normalized XAS spectra.

Reference materials $\mathrm{CuO}$ and $\mathrm{CuSO}_{4}$ were prepared as pellets (using pestle and mortar, then with pellet press) and used for qualitative comparison of XAS data. XAS measurements of references (and $\mathrm{Cu}$ foil) were collected in transmission mode at the I-14 nanoprobe using a photodiode detector. Additional references were sent by Alain Manceau for comparison to BW$1 \mathrm{XAS}^{4}{ }^{4}$ These spectra were energy calibrated to their respective $\mathrm{Cu}$ foil. Athena program from the Demeter package was employed to conduct XAS data normalization and energy calibration.

\section{Cryo-ET}

BW-1 cells sample ( $4 \mu \mathrm{L})$ with $10 \mathrm{~nm}$ gold beads $(1 \mu \mathrm{L})$ were applied to glow-discharged holey carbon R2/1 Cu 200 mesh grids (Quantifoil). The grids were blotted and vitrified using a Leica EM-GP automatic plunger under $18^{\circ} \mathrm{C}$ and $90 \%$ humidity conditions. Frozen grids were kept in liquid nitrogen until used. Cryo-ET data was collected on a Titan Krios TEM G3i (Thermo Fisher Scientific) equipped with an energy filter and a K3 direct electron detector (Gatan Inc.). 
Data sets were collected at $300 \mathrm{kV}$ with the $\mathrm{K} 3$ camera (counting mode) and Volta phase plate using the Thermo Fisher Tomography software. The TEM magnification corresponded to a camera pixel size of $8.03 \AA$ for tomograms collected at X11,500 magnification and $4.54 \AA$ for tomograms collected at X19,500 magnification and (K3 counting mode), and the target defocus was set between -10 and $-30 \mu \mathrm{m}$. The total dose for a full tilt series was about 100 electron per $\AA^{2}$. Tomogram tilt ranges were between $\left(40^{\circ}\right.$ or $\left.60^{\circ}\right)$ to $\left(-40^{\circ}\right.$ or $\left.-60^{\circ}\right)$ with $2^{\circ}$ to $10^{\circ}$ steps.

\section{Cryo-ET data analysis and $3 D$ representation}

The tilt series images alignment and reconstruction were performed in IMOD. Segmentation and 3D representation of the reconstructed tomographic data was done using Amira ${ }^{\circledR}$ software (Thermo Scientific). Data segmentation was performed based on contrast variations following the unique shape and structure of each component.

\section{Protein analysis with nanoLC-tandem MS}

Cultures of $400 \mathrm{~mL}$ with $\mathrm{Cu}$ (II) $13.9 \mu \mathrm{M}$ or with $\mathrm{Cu}$ (II) $0.73 \mu \mathrm{M}$ were prepared in triplicate and inoculated from a same pre-culture with the same amount of cells, about $10^{6}$ cells $\times \mathrm{ml}^{-1}$. After 20 hours of cultivation, cells were harvested by centrifugation at 20,000 g for $30 \mathrm{~min}$ at $28^{\circ} \mathrm{C}$. The supernatants were removed and the bacterial pellets consisting of about $5 \mathrm{mg}$ (wet weight) of cells were quickly frozen in liquid nitrogen, and then kept at $-80{ }^{\circ} \mathrm{C}$. Proteins were extracted from bacterial pellets and subjected to a $5 \mathrm{~min}$ SDS-PAGE electrophoresis as recommended (28). The whole proteome was subjected to in-gel trypsin proteolysis and the resulting peptides were characterized by tandem mass spectrometry performed with a QExactive HF instrument (Thermo) coupled to a nanoUPLC in similar conditions as previously described (29). MS/MS spectra were interpreted against the Desulfamplus Magnetovallimortis BW-1 theoretical annotated proteome with Mascot Daemon software version 2.6.1 (Matrix Science), taking into consideration a parent peptide tolerance of $5 \mathrm{ppm}$ and MS/MS fragment tolerance of $0.02 \mathrm{Da}$. Peptides and proteins were identified with a false-positive rate of $1 \%$. Comparison of protein abundance between culture conditions was performed using the TFold test on the basis of the number of MS/MS spectra assigned per protein (spectral counts) as proxy of protein abundances as recommended (22). The list of CDS used in this study for proteomics was obtained using the functional annotation performed with the MicroScope platform (30) and the genome of Desulfamplus Magnetovallimortis strain BW-1 published by Lefèvre et al. (23) (RefSeq assembly accession number GCF_900170035.1) 